\title{
Anti-inflammatory action of ambuic acid, a natural product isolated from the solid culture of Pestalotiopsis neglecta, through blocking ERK/JNK mitogen-activated protein kinase signaling pathway
}

\author{
QIAN ZHANG $^{1 *}$, RUILING LUAN $^{2 *}$, HUIXIANG LI $^{1}$, YANAN LIU $^{1}$, PAN LIU $^{1}$, LIYING WANG $^{1}$, \\ DANNA LI ${ }^{1}$, MENGDI WANG ${ }^{1}$, QIANG ZOU ${ }^{3}$, HONGWEI LIU ${ }^{4}$, KEIICHI MATSUZAKI ${ }^{5}$ and FENG ZHAO ${ }^{1}$ \\ ${ }^{1}$ School of Pharmacy, Key Laboratory of Molecular Pharmacology and Drug Evaluation, Ministry of Education, \\ Collaborative Innovation Center of Advanced Drug Delivery System and Biotech Drugs in Universities of Shandong, \\ Yantai University, Yantai, Shandong 264003; ${ }^{2}$ Pharmacy Dispensing Center, The Affiliated Yantai Yuhuangding Hospital of \\ Qingdao University, Yantai, Shandong 264000; ${ }^{3}$ Yantai Branch of Shandong Technology Transfer Center, Chinese Academy \\ of Sciences, Yantai, Shandong 264003; ${ }^{4}$ State Key Laboratory of Mycology, Institute of Microbiology, Chinese Academy \\ of Sciences, Beijing 100101, P.R. China; ${ }^{5}$ School of Pharmacy, Nihon University, Funabashi, Chiba 274-8555, Japan
}

Received March 8, 2017; Accepted April 24, 2018

DOI: $10.3892 /$ etm.2018.6294

\begin{abstract}
Ambuic acid is an organic acid isolated from the solid culture of Pestalotiopsis neglecta, which is an endophytic fungus that widely exists in many species of plants. Ambuic acid has been reported to exert antimicrobial activity against Gram-positive bacterium. The aim of the present study was to investigate the inhibitory effect of ambuic acid on lipopolysaccharide (LPS)-induced inflammation in RAW264.7 macrophages. The results demonstrated that ambuic acid significantly suppressed the overproduction of nitric oxide (NO) and prostaglandin $\mathrm{E}_{2}\left(\mathrm{PGE}_{2}\right)$ in a dose-dependent manner. Furthermore, ambuic acid also inhibited the release of the proinflammatory cytokine interleukin-6 (IL-6) however, no inhibition of the release of tumor necrosis factor- $\alpha$
\end{abstract}

Correspondence to: Dr Feng Zhao, School of Pharmacy, Key Laboratory of Molecular Pharmacology and Drug Evaluation, Ministry of Education, Collaborative Innovation Center of Advanced Drug Delivery System and Biotech Drugs in Universities of Shandong, Yantai University, 30 Qingquan Road of Laishan District, Yantai, Shandong 264003, P.R. China

E-mail: ytuzhaofeng@163.com

Professor Hongwei Liu, State Key Laboratory of Mycology, Institute of Microbiology, Chinese Academy of Sciences, 1 Beichen West Road, Chaoyang, Beijing 100101, P.R. China

E-mail: liuhw@im.ac.cn

${ }^{*}$ Contributed equally

Key words: ambuic acid, Pestalotiopsis neglecta, Anti-inflammatory activity, inducible nitric oxide synthase, cyclooxygenase-2, mitogen-activated protein kinase
(TNF- $\alpha$ ) was observed. Further investigations indicated that ambuic acid downregulated the LPS-induced high expression of inducible NO synthase (iNOS) and cyclooxygenase-2 (COX-2) proteins, as well as inhibited the enzymatic activity of iNOS and COX-2. In addition, ambuic acid suppressed the phosphorylation of extracellular signal-regulated kinase $1 / 2$ (ERK 1/2) and c-Jun N-terminal kinase (JNK) induced by LPS. However, ambuic acid did not inhibit the phosphorylation of p38 mitogen-activated protein kinase (MAPK), the degradation of $I \kappa B-\alpha$ protein or the nuclear translocation of nuclear transcription factor- $\kappa \mathrm{B}(\mathrm{NF}-\kappa \mathrm{B}) \mathrm{p} 65$ subunit. These results suggested that ambuic acid may exert anti-inflammatory action by blocking the activation of the ERK/JNK MAPK signaling pathway, without the involvement of the p38 MAPK or NF- $\kappa B$ signaling pathways.

\section{Introduction}

The endophytic is a fungi of the genus Pestalotiopsis which exists widely in many plants of different families, have received wide attention because of their ability in producing a variety of secondary metabolites, such as caryophyllene sesquiterpenoids $(1,2)$, disseminins and spiciferone analogues (3), prenyldepside and coumarins (4), diphenyl ether derivatives (5), benzannulated spiroketals (6), chromones (7), 1,3-dihydro isobenzofuran (8), epoxyquinols (9), and polyketide derivatives (10). It is reported that the well-known anticancer drug taxol has been found from several cultivated species of the genus Pestalotiopsis, which provides another alternative way to produce such valuable anti-cancer drugs $(11,12)$. The active secondary metabolites produced by the endophytic fungi can stimulate the growth and development of the organisms, or improve the ability of the host to resist the external environment (13). Pharmacological researches have revealed that the secondary metabolites from species of Pestalotiopsis 
possess diverse pharmacological properties, including antimicrobial activity (14-16), antiviral (17), antitumor (18), anti-diabetic activity (19), immunomodulatory activity (20), anticestodal activity (21), antioxidant and antihypertensive properties (22), and 20S proteasome inhibitory activity (23).

Ambuic acid (chemical structure shown in Fig. 1) was firstly reported as a novel functionalized cyclohexenone initially isolated from Pestalotiopsis spp. and Monochaetia $s p$. in 2001 (24), and its relative stereochemistry was predicted by using a novel solid-state nuclear magnetic resonance (NMR) approach in 2003 (25). Ambuic acid showed a certain inhibitory effect on a variety of plant pathogenic fungi Fusarium solani, Fusarium cubense, Helminthosporium sativum, Diplodia natelensis, Cephalosporium gramineum, Pythium ultimum (24), and it has a certain antimicrobial activity against the Gram-positive bacterium Staphyococcus aureus (26). Ambuic acid can also effect the biosynthesis of cyclic peptide quormones in Gram-positive bacteria and Enterococcus faecalis (27). In our recent studies, a plant pathogenic fungus Pestalotiopsis neglecta (FJ-2) has been separated from the twig of Camellia sinensis growing in Fujian Province of China. Futhermore, four new ambuic acid derivatives together with ambuic acid and three other known ramification, have been isolated and identified from the solid culture of Pestalotiopsis neglecta (28). Inhibitory activities of these compounds against LPS-induced overproduction of nitric oxide (NO) in macrophages have been evaluated. Ambuic acid exhibited strong inhibitory activity with $\mathrm{IC}_{50}$ value of $20.80 \pm 1.41 \mu \mathrm{M}$, which was even much potent than the positive control drug.

Macrophages play an important role in providing immediate defense against foreign stimuli. Lipopolysaccharide (LPS)-mediated overproduction of NO and subsequent inflammatory reaction by macrophages is proved to be closely associated with many pathogenic diseases, including rheumatoid arthritis (29), cancer (30), atherosclerosis (31), and hepatitis (32). By reducing NO formation or removing NO molecule, NO inhibitors may be used as powerful therapeutic anti-inflammatory agents (33). In the present paper, the anti-inflammatory effect of ambuic acid as a NO inhibitor was firstly investigated and the molecular mechanism of the anti-inflammatory action of ambuic acid was absolutely elucidated.

\section{Materials and methods}

Fungal material. The pathogenic strain (FJ-2) used in this work was separated from the twig of Camellia sinensis growing in Fujian Province of China. The identification of fungus was based on the (deoxyribonucleic acid) DNA sequences of the ITS1-5.8S-ITS2, and the ITS regions of their ribosomal ribonucleic acid (RNA) gene. We have submitted the sequence data derived from the fungal strain and stored them at GenBank with accession number KJ719299. The result of BLAST search showed that the similarity between the sequence and the sequence of Pestalotiopsis neglecta (Thüm.) was $99 \%$. It was stored in GenBank with the accession number of JX854541.

The fungal strain was placed on the slants of potato dextrose agar and cultured at $25^{\circ} \mathrm{C}$ for 10 days. We inoculated the agar

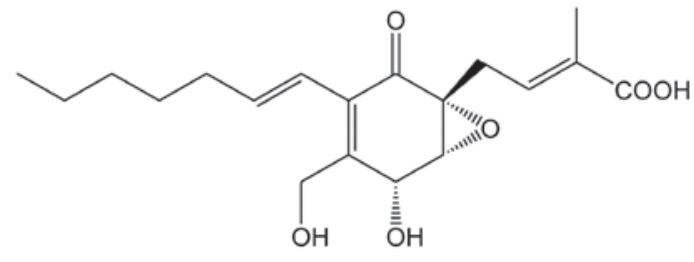

Figure 1. Chemical structure of ambuic acid.

plugs in $500 \mathrm{ml}$ Erlenmeyer flask, it contains $120 \mathrm{ml}$ of media ( $0.4 \%$ glucose, $1 \%$ malt extract, and $0.4 \%$ yeast extract, before sterilization the final $\mathrm{pH}$ of the medium was adjusted to 6.5), and it was incubated at $25^{\circ} \mathrm{C}$ on a rotary shaker at $180 \mathrm{rpm}$ for 4 days. Large scale fermentation taked place in 40 bottles of $500 \mathrm{ml}$ Fernbach flasks, which containing $80 \mathrm{~g}$ of rice and $100 \mathrm{ml}$ of distilled water. Each flask was inoculated with $10.0 \mathrm{ml}$ of culture medium and cultured at $25^{\circ} \mathrm{C}$ for 40 days.

Isolation and identification of ambuic acid. The ethyl acetate was used to extract the fermented rice substrate, and the organic solvent was decompressed and concentrated to obtain the crude extract, silica gel column chromatography (CC) with a gradient of n-hexane-ethyl acetate, dichloromethane-methanol were used to divided them into five groups (A-E).

Fraction $\mathrm{C}$ was treated with dichloromethane-methanol and subjected to ODS CC eluting with a gradient of methanol in water $(10 \% \sim 100 \%)$ to obtain twenty-one subfractions (C1-C21). Subfraction C13 was separated by RP-HPLC using $63 \%$ methanol in water to afford ambuic acid. Its chemical structure was validated by extensive NMR experiments and validated by comparison with the data previously incorpratated into the databases of SciFinder Scholar and PubChem. The purity was determined using high-performance liquid chromatography (HPLC; Waters 600; Waters Corp., Milford, MA, USA) and a ultraviolet detector (Waters 490; Waters Corp.); peak area was normalized and the purity of ambuic acid was $98.7 \%$.

Chemicals and reagents. Fetal bovine serum (FBS) and RPMI 1640 culture medium were purchased from Invitrogen (Thermo Fisher Scientific, Inc., Waltham, MA, USA). LPS, DMSO, MTT, PMSF and all other chemicals were obtained from Sigma-Aldrich; Merck KGaA (Darmstadt, Germany). Hydrocortisone succinate (080-05581, Lot CTE6574) was product of Wako Pure Chemical Industries, Ltd. (Osaka, Japan). NO concentration determination kit, mouse prostaglandin E2 (PGE2) ELISA kit, mouse tumor necrosis factor- $\alpha$ (TNF- $\alpha$ ) ELISA kit, mouse interleukin-6 (IL-6) ELISA kit, and BCA protein concentration assay kit were purchased from Yantai Science and Biotechnology Co., Ltd. (Shandong, China). NO synthase (NOS) assay kit (fluorimetric method) was product of Beyotime Institute of Biotechnology (Haimen, China). COX colorimetric inhibitor screening assay kit (701050) was product of Cayman Chemical Company (Ann Arbor, MI, USA). Mouse anti-rabbit inducible NOS (iNOS) polyclonal antibody (160862) and mouse anti-rabbit cyclooxygenase-2 (COX-2) polyclonal antibody (160106) were purchased from Cayman Chemical Company. Goat anti-rabbit phosphorylated c-Jun N-terminal kinase (p-JNK) polyclonal antibody (AF3318), 
goat anti-rabbit phosphorylated extracellular signal-regulated kinase 1/2 (p-ERK 1/2) polyclonal antibody (AF1015), goat anti-rabbit phosphorylated p38 (p-p38) polyclonal antibody (AF3455), and horseradish peroxidase (HRP)-conjugated goat anti-rabbit IgG $(\mathrm{H}+\mathrm{L})$ (S0001) were products of Affinity Biosciences. Goat anti-rabbit I B B- $\alpha$ polyclonal antibody (sc-371), mouse monoclonal nuclear transcription factor- $\kappa \mathrm{B}$ $(\mathrm{NF}-\kappa \mathrm{B})$ p65 antibody (sc-8008), and goat anti-rabbit $\beta$-actin polyclonal antibody (sc-1616) were purchased from Santa Cruz Biotechnology, Inc. A solution for dissolving ambuic acid with $100 \%$ cell culture grade dimethyl sulfoxide (DMSO) into $50 \mathrm{mM}$ and stored as small aliquots at $-20^{\circ} \mathrm{C}$ and then diluted it to desired concentrations prior to use.

Cell culture. Mouse monocyte-macrophage RAW264.7 cells (ATCC TIB-71; American Type Culture Collection, Manassas, VA, USA) were cultured in RPMI-1640 medium supplemented with $10 \%$ heat inactivated FBS in a humidified incubator with $95 \%$ air and $5 \% \mathrm{CO}_{2}$ at $37^{\circ} \mathrm{C}$. Every two days, the medium was routinely changed. When the cells attained about $80 \%$ confluence, they were passaged.

MTT assay for cytotoxicity. Using the measured of mitochondrial-dependent reduction of MTT to formazan to measure the cytotoxicity (34). RAW264.7 cells were seeded in 96-well plates at the density of $1 \times 10^{6}$ cells/ml. After $1 \mathrm{~h}$ of incubation, the cells were treated with serially diluted ambuic acid (the concentrations were from 0.78125 to $100 \mu \mathrm{M}$ ) and incubated for $24 \mathrm{~h}$. After treatment, adding MTT solution with the concentration of $200 \mu \mathrm{g} / \mathrm{ml}$, and set the cells to the incubator for another $4 \mathrm{~h}$ at $37^{\circ} \mathrm{C}$. Removing the medium and adding $150 \mu \mathrm{l}$ of DMSO to dissolve the formazan. Using the microplate reader at $570 \mathrm{~nm}$ to measure the absorbance of each group and using a reference wavelength at $630 \mathrm{~nm}$ (Biotek Synergy HT; BioTek Instruments, Inc., Winooski, VT, USA). The control group, consisting of untreated cells, was considered to be $100 \%$ viable. Final results are expressed as percentage of viable cells of the experimental group when compared with those of the control group.

NO analysis. NO was determined through measuring the nitrite concentration in the cell culture supernatant by using Griess reagent (mixture of equal amount of reagent $\mathrm{A}$ and reagent $\mathrm{B}$; $\mathrm{A}$ : $1 \%$ sulphanilamide in $5 \% \mathrm{H}_{3} \mathrm{PO}_{4}, \mathrm{~B}: 0.1 \%$ naphthylethylene diamine dihydrochloride) (35). RAW264.7 cells were seeded in 96-well plates at the density of $1 \times 10^{6}$ cells $/ \mathrm{ml}$. After $1 \mathrm{~h}$ incubation, the cells were treated by LPS $(1 \mu \mathrm{g} / \mathrm{ml})$ with or without ambuic acid $(3.125,6.25,12.5,25,50,100 \mu \mathrm{M})$, or hydrocortisone succinate $(100 \mu \mathrm{M})$ and then incubated for $24 \mathrm{~h} .100 \mu \mathrm{l}$ of the cell culture supernatant was mixed with $100 \mu \mathrm{l}$ of Griess reagent and shaked for $10 \mathrm{~min}$ at room temperature. The absorbance was measured at $540 \mathrm{~nm}$, and using a standard calibration curve to calculate the nitrite concentrations which was prepared from a range of different concentrations of sodium nitrite.

$P G E_{2}$ concentration determination. $\mathrm{PGE}_{2}$, a pro-inflammatory mediator, is produced by COX-2. RAW264.7 cells were treated by LPS $(1 \mu \mathrm{g} / \mathrm{ml})$ with or without ambuic acid $(3.12$, $6.25,12.5,25,50,100 \mu \mathrm{M})$, or hydrocortisone succinate
$(100 \mu \mathrm{M})$ for $24 \mathrm{~h}$. The cell culture supernatant of $100 \mu \mathrm{l}$ was removed to determine the level of $\mathrm{PGE}_{2}$ by using a commercial mouse $\mathrm{PGE}_{2}$ ELISA kit according to the manufacturer's recommendations. The ELISA data representing mean values \pm SD (standard deviation) were obtained in duplicate from three independent experiments (36).

Measurement of cytokines TNF- $\alpha$ and IL-6. RAW264.7 cells were seeded in 96-well plates at the density of $5 \times 10^{5}$ cells $/ \mathrm{ml}$. After $1 \mathrm{~h}$ incubation, the cells were treated by LPS $(1 \mu \mathrm{g} / \mathrm{ml})$ with or without ambuic acid $(3.12,6.25,12.5,25,50,100 \mu \mathrm{M})$, or hydrocortisone succinate $(100 \mu \mathrm{M})$ for $6 \mathrm{~h}$. $100 \mu \mathrm{l}$ of the culture supernatants was collected to determine the levels of TNF- $\alpha$ or IL- 6 by using respective ELISA kit according to the manufacturer's recommendations (37). The ELISA data representing mean values $\pm \mathrm{SD}$ were obtained in duplicate from three independent experiments.

Assay of iNOS enzymatic activity. Methods for the determination of iNOS enzymatic activity as previously reported (38). Briefly, after the treatments, removing the culture supernatant, and adding $100 \mu \mathrm{l}$ of NOS assay buffer (1X). Then adding $100 \mu \mathrm{l}$ of NOS assay reaction solution and incubated for $2 \mathrm{~h}$ at $37^{\circ} \mathrm{C}$. Using fluorescence microplate reader measured the fluorescence at excitation wavelength of $485 \mathrm{~nm}$ and emission wavelength of $528 \mathrm{~nm}$.

Assay of COX-2 enzymatic activity. The enzymatic activity of COX-2 was determined in a cell-free system by using a COX colorimetric inhibitor screening assay kit according to the manufacturer's instructions (38). Briefly, $160 \mu \mathrm{l}$ of assay buffer, $10 \mu \mathrm{l}$ of heme, and $10 \mu \mathrm{l}$ of DMSO were added to the background wells. $150 \mu \mathrm{l}$ of assay buffer, $10 \mu \mathrm{l}$ of COX-2 enzyme, $10 \mu \mathrm{l}$ of heme, and $10 \mu \mathrm{l}$ of DMSO were added to the $100 \%$ initial activity wells. $150 \mu \mathrm{l}$ of assay buffer, $10 \mu \mathrm{l}$ of COX-2 enzyme, $10 \mu l$ of heme, and $10 \mu \mathrm{l}$ of ambuic acid or hydrocortisone succinate were added to the sample wells. The plate was gently shaken for a few sec and then incubated for five min at $25^{\circ} \mathrm{C}$. Adding $20 \mu \mathrm{l}$ of the colorimetric substrate solution and then adding $20 \mu \mathrm{l}$ of arachidonic acid to all the wells. Shaking the plate carefully for a few sec and incubating it for five min at $25^{\circ} \mathrm{C}$. The absorbance was measured at $590 \mathrm{~nm}$ by using a microplate reader, and the enzymatic activity of COX-2 was calculated when compared with the $100 \%$ initial activity wells according to the manufacturer's instructions.

Total protein extraction. To determination the expression of iNOS and COX-2 proteins, adding the LPS $(1 \mu \mathrm{g} / \mathrm{ml})$ to the RAW264.7 cells with or without indicated concentrations of ambuic acid for $24 \mathrm{~h}$. Then washing it with ice-cold phosphate-buffered saline (PBS), harvesting the cells and adding $40 \mu \mathrm{l}$ of cold lysis buffer [10\% NP-40, $150 \mathrm{mM} \mathrm{NaCl}$, $10 \mathrm{mM}$ Tris, $2 \mathrm{mM}$ PMSF, $5 \mu \mathrm{M}$ leupeptin, $\mathrm{pH}$ 7.6] to lyse the cell. For determination of phospho-JNK, phospho-ERK 1/2, and phospho-p38 proteins, added the LPS $(1 \mu \mathrm{g} / \mathrm{ml})$ to the RAW264.7 cells with or without indicated concentrations of ambuic acid for $30 \mathrm{~min}$. Then washing it with ice-cold PBS, harvesting the cells and adding $40 \mu \mathrm{l}$ of the same cold lysis buffer mentioned above to lyse the cell. After incubating at $4^{\circ} \mathrm{C}$ for $15 \mathrm{~min}$, centrifuging it at $15,000 \times \mathrm{g}$ for $10 \mathrm{~min}$ at 
$4^{\circ} \mathrm{C}$, the total proteins were separated and used for western blot analysis.

Cytoplasmic and nuclear protein extraction. After proper treatments, removing the media, and washing the cells with ice-cold PBS, then harvesting the cells and adding $40 \mu \mathrm{l}$ of buffer A [10 mM HEPES, $1.5 \mathrm{mM} \mathrm{MgCl}_{2}, 10 \mathrm{mM} \mathrm{KCl,} 500 \mu \mathrm{M}$ DTT, $0.1 \%(\mathrm{v} / \mathrm{v}) \mathrm{NP}-40]$ to lyse the cell. After incubating at $4^{\circ} \mathrm{C}$ for $15 \mathrm{~min}$, centrifuging it at $12,000 \mathrm{x}$ for $5 \mathrm{~min}$ at $4^{\circ} \mathrm{C}$, the cytoplasmic proteins were separated and used for western blot analysis of I $\mathrm{B}-\alpha$. The ectraction of nuclei pellet is to suspend precipitation in $30 \mu \mathrm{l}$ of buffer B [20 mM HEPES, $1.5 \mathrm{mM}$ $\mathrm{MgCl}_{2}, 400 \mathrm{mM} \mathrm{NaCl}, 100 \mathrm{mM}$ DTT, $20 \mu \mathrm{M}$ PMSF] and incubated for $20 \mathrm{~min}$ at $4^{\circ} \mathrm{C}$. By centrifuging at $16,000 \mathrm{x} \mathrm{g}$ for $10 \mathrm{~min}$ at $4^{\circ} \mathrm{C}$, the supernatant was separated as nuclear protein and used for western blot analysis of NF- $\kappa \mathrm{B}$ p 65 subunit.

Western blotting. Using the BCA protein concentration assay kit to determine the protein concentration of each aliquot, and the suspensions were boiled with SDS-PAGE loading buffer. The $30 \mu \mathrm{g}$ of protein in each sample were transferred to the nitrocellulose membranes by SDS-PAGE and electrophoretically. The membranes were blocked with 5\% non-fat dried milk in Tris-buffered saline and Tween-20 (TBST, $20 \mathrm{mM}$ Tris- $\mathrm{HCl}, 150 \mathrm{mM} \mathrm{NaCl}, 0.05 \%$ Tween20) for $4 \mathrm{~h}$ at room temperature. After washed with TBST, incubating the membranes in respective primary antibody solution (anti-iNOS, anti-COX-2, anti-phospho-JNK, anti-phospho-ERK, anti-phospho-p38, anti-IкB- $\alpha$, anti-p65, and anti- $\beta$-actin antibody) overnight at $4{ }^{\circ} \mathrm{C}$. Washing the membranes with TBST and then incubating them with HRP-conjugated secondary antibody solution for $1 \mathrm{~h}$ at room temperature. The membranes were washed three times with TBST and the blots were detected by using enhanced chemiluminescence reagent (ECL) and exposed to photographic films (Kodak, Rochester, NY, USA). Images were collected and the bands corresponding to iNOS, COX-2, phospho-ERK, phospho-JNK, phospho-p38, IкB- $\alpha$, p65 and $\beta$-actin protein were quantitated by densitometric analysis using the DigDoc100 program (Alpha Ease FC software). Data of iNOS, COX-2, phospho-ERK, phospho-JNK, phospho-p38, IкB- $\alpha$ and p65 were normalized on the basis of $\beta$-actin levels.

Statistical analysis. All data were shown as mean \pm SD. Significant differences among different treatment groups were analyzed by two-way analysis of variance (ANOVA) followed by the post hoc Bonferroni test. $\mathrm{P}<0.05$ was considered to indicate a statistically significant difference.

\section{Results}

Ambuic acid did not exhibit cytotoxicity against RAW264.7 macrophages at the concentrations of 0.78-25 $\mu$ M. RAW264.7 cells were treated by $0.78-100 \mu \mathrm{M}$ of ambuic acid for $24 \mathrm{~h}$. MTT assay described in the section of Materials and methods was used to test the cell viability. As shown in Fig. 2, treatment with $100 \mu \mathrm{M}$ and $50 \mu \mathrm{M}$ of ambuic acid showed weak cytotoxicity against RAW264.7 cells, but no cytotoxicity was observed at the dose range of $0.78-25 \mu \mathrm{M}$.

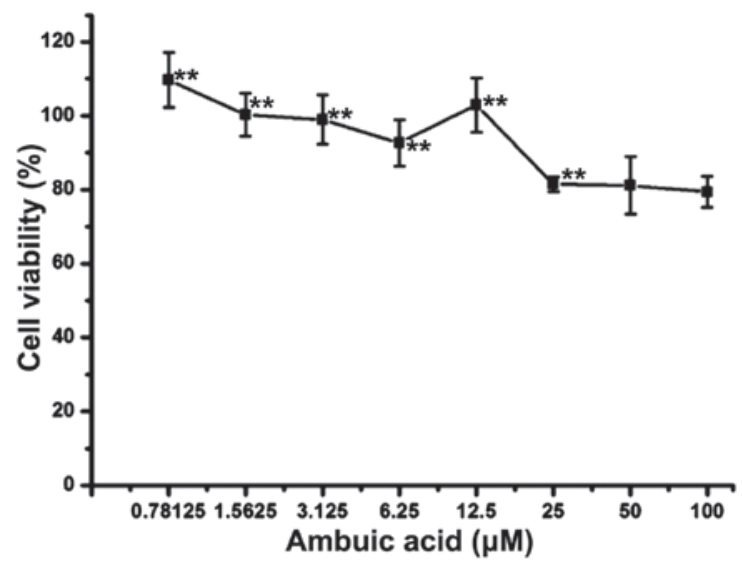

Figure 2. Cellular toxicity of ambuic acid against RAW264.7 cells RAW264.7 cells were treated with serially diluted doses of ambuic acid $(0.78125,1.5625,3.125,6.25,12.5,25,50$ and $100 \mu \mathrm{M})$ for $24 \mathrm{~h}$ and the cell viability was assessed by the MTT assay. The percentage of viable cells was compared with the untreated cells which were considered as having $100 \%$ of viable cells. Data are presented as mean \pm standard deviation of at least three independent experiments. ${ }^{* *} \mathrm{P}<0.01$ vs. untreated group.

Effect of ambuic acid on the $N O$ and $P G E_{2}$ production. RAW264.7 cells were treated by $1 \mu \mathrm{g} / \mathrm{ml}$ of LPS with or without ambuic acid $(3.125,6.25,12.5,25,50,100 \mu \mathrm{M})$, or hydrocortisone succinate $(100 \mu \mathrm{M})$ for $24 \mathrm{~h}$. The concentration of nitrite $\left(\mathrm{NO}_{2}^{-}\right)$was monitored by Griess assay as indicator of $\mathrm{NO}$ production, and the level of $\mathrm{PGE}_{2}$ was determined by ELISA. Hydrocortisone succinate was used as a positive control drug. As shown in Fig. 3A, ambuic acid significantly inhibited the overproduction of NO induced by LPS in a dose-dependent manner. However, the production of $\mathrm{PGE}_{2}$ induced by LPS was only weakly inhibited by ambuic acid (Fig. 3B).

Effect of ambuic acid on the TNF- $\alpha$ and IL- 6 release. RAW264.7 cells were treated by $1 \mu \mathrm{g} / \mathrm{ml}$ of LPS with or without ambuic acid $(3.125,6.25,12.5,25,50$ and $100 \mu \mathrm{M})$, or hydrocortisone succinate $(100 \mu \mathrm{M})$ for $6 \mathrm{~h}$. The levels of pro-inflammatory cytokine TNF- $\alpha$ and IL- 6 were measured by using respective ELISA kit. As shown in Fig. 3C, the positive control group hydrocortisone succinate potently can effectively inhibit the release of inflammatory factor TNF- $\alpha$ induced by LPS. However, ambuic acid did not show any significant inhibitory activity on the release of inflammatory factor TNF- $\alpha$. As shown in Fig. 3D, ambuic acid significantly inhibited the release of IL- 6 induced by LPS in a dose-dependent manner.

Effect of ambuic acid on the expression of iNOS and COX-2 proteins. As the overproduction of $\mathrm{NO}$ and $\mathrm{PGE}_{2}$ is always correlated with the high expression of iNOS andCOX-2 proteins, and we currently using Western blot analysis to investigate the expression of iNOS together with COX-2 protein. As shown in Fig. 4A, the expression of iNOS and COX-2 proteins was potently increased after stimulation of LPS for $24 \mathrm{~h}$. Ambuic acid can markedly down regulated the expression of iNOS protein in a dose-dependent manner, which strongly suggested that the decrease of NO production was due to the inhibitory effect of ambuic acid on the suppression of iNOS expression. Furthermore, ambuic acid also inhibited the expression of COX-2 protein. The density of bands corresponding to the 
A
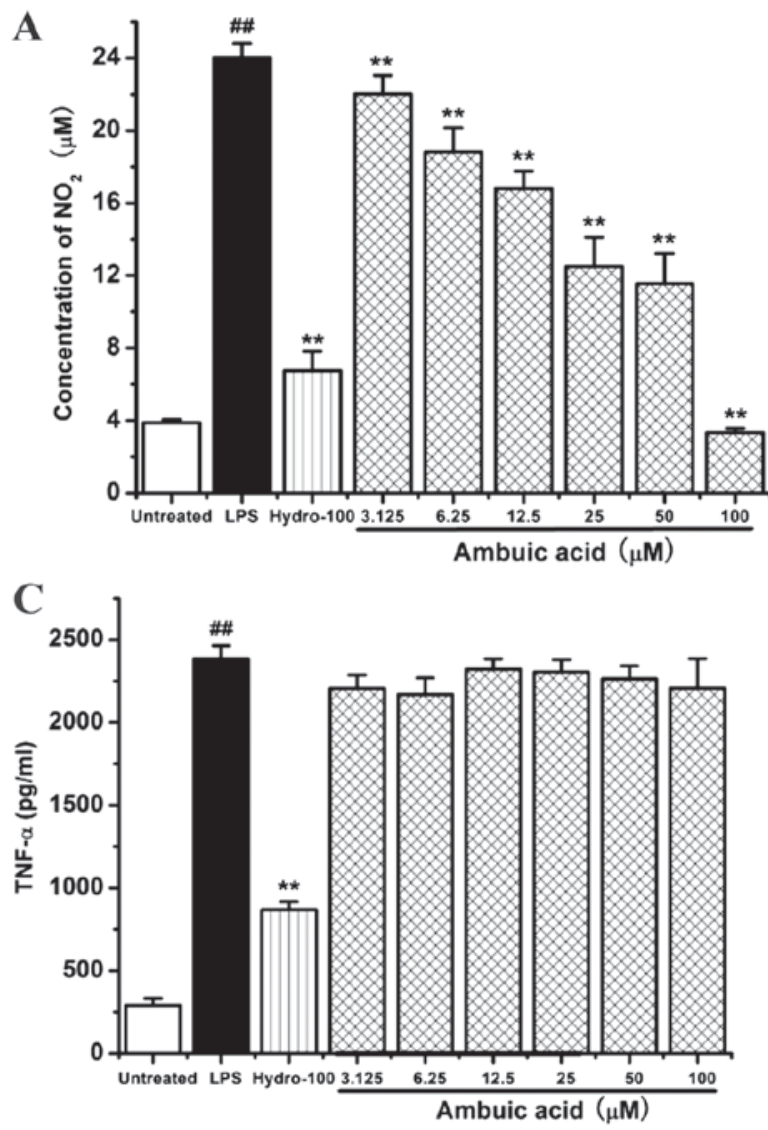
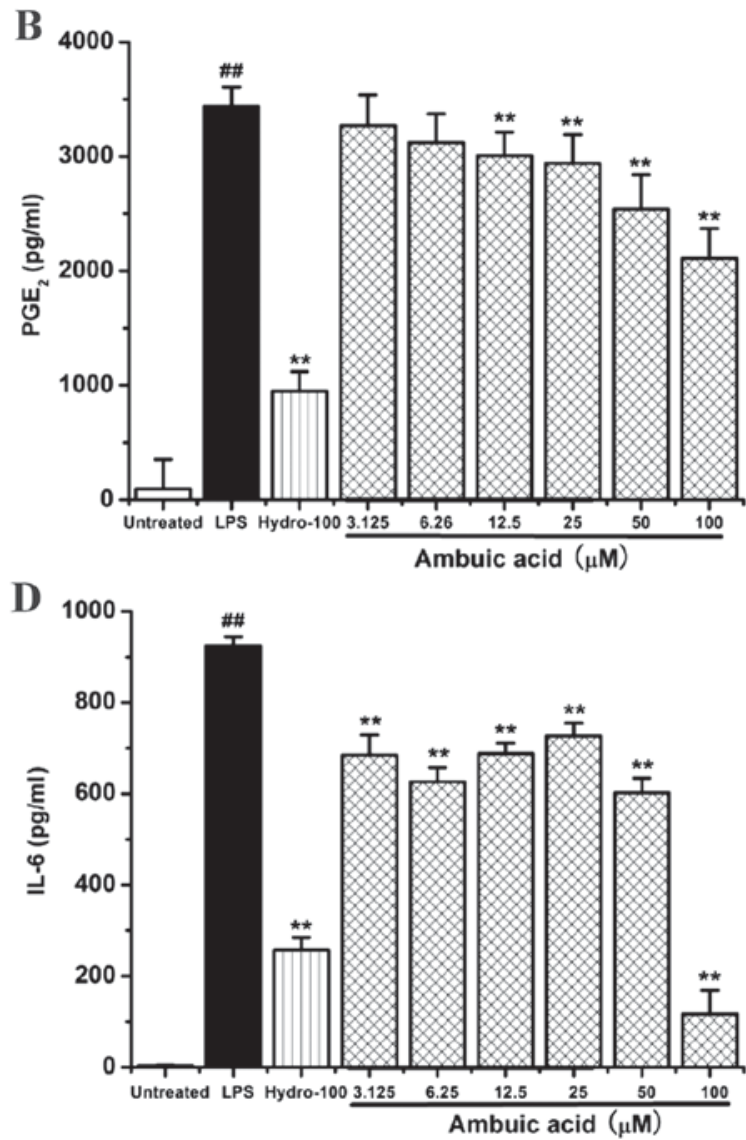

Figure 3. Effect of ambuic acid on the overproduction of (A) $\mathrm{NO}_{2}$, (B) PGE 2 and the release of (C) TNF- $\alpha$, (D) IL-6 in LPS-activated macrophages. RAW264.7 cells were stimulated by $1 \mu \mathrm{g} / \mathrm{ml}$ LPS with or without ambuic acid $(3.125,6.25,12.5,25,50$ and $100 \mu \mathrm{M})$ or hydrocortisone succinate (100 $\mu \mathrm{M})$ for $24 \mathrm{~h}$. (A) The nitrite concentrations in the supernatant were calculated in triplicate by Griess assay. (B) The levels of PGE 2 in the supernatant were measured in triplicate by ELISA. RAW264.7 cells were stimulated by $1 \mu \mathrm{g} / \mathrm{ml}$ LPS with or without ambuic acid $(3.125,6.25,12.5,25,50$ and $100 \mu \mathrm{M})$ or hydrocortisone succinate $(100 \mu \mathrm{M})$ for $6 \mathrm{~h}$. The levels of (C) TNF- $\alpha$ and (D) IL-6 in the supernatant were measured in triplicate by respective ELISA kit. Data are presented as mean \pm standard deviation from three separate experiments. ${ }^{\#} \mathrm{P}<0.01$ vs. untreated group, ${ }^{* *} \mathrm{P}<0.01$ vs. LPS treatment group. NO, nitric oxide; PGE 2 prostaglandin E2; TNF- $\alpha$, tumor necrosis factor- $\alpha$; IL-6, interleukin-6; LPS, lipopolysaccharide.

iNOS and COX-2 proteins were standardized on the basis of $\beta$-actin and shown in Fig. 4B and C, respectively.

Effect of ambuic acid on the iNOS and COX-2 enzymatic activity. RAW264.7 cells were treated by $1 \mu \mathrm{g} / \mathrm{ml}$ of LPS with or without indicated concentrations of ambuic acid $(12.5,25$, 50 and $100 \mu \mathrm{M})$ or hydrocortisone succinate $(100 \mu \mathrm{M})$. The inhibitory effect of ambuic acid at different concentration on the activity of iNOS enzymatic activity was detected by fluorimetric method. As shown in Fig. 5A, LPS treatment caused about a six-fold increase of iNOS enzymatic activity within $120 \mathrm{~min}$. Ambuic acid could significantly inhibit the activity of iNOS enzymatic induced by LPS in RAW264.7 cells and showed a good dose-dependency.

The inhibitory effect of ambuic acid on the COX-2 enzymatic activity was examined by the cell-free colorimetric method. As shown in Fig. 5B, ambuic acid also inhibited the COX-2 enzymatic activity.

Effect of ambuic acid on the activation of mitogen-activated protein kinase (MAPK) signaling pathway. Previous studies have already demonstrated that the MAPK signaling pathways are associated with the upregulation of LPS-induced inflammatory responses. LPS activates MAPKs including the protein kinases ERK 1/2, JNK and p38 kinase. In order to investigate whether the three MAPK protein pathways are involved in the anti-inflammatory responses by ambuic acid, LPS-induced phosphorylation of ERK1/2, JNK and p38 in RAW264.7 cells were examined by Western blot analysis. As shown in Fig. 6, LPS treatment significantly induced the phosphorylation of ERK 1/2, JNK and p38. Ambuic acid could remarkably reduced LPS-induced phosphorylation of ERK1/2 and JNK in a dose-dependent manner, whereas phosphorylation of p38 was not affected. The density of bands corresponding to the phospho-ERK, phospho-JNK and phospho-p38 protein was standardized on the basis of $\beta$-actin and shown in Fig. 6.

Effect of ambuic acid on the activation of $N F-\kappa B$ signaling pathway. NF- $\kappa \mathrm{B}$ translocated to the nucleus always due to the phosphorylation and degradation of $\mathrm{I} \kappa \mathrm{B}-\alpha$ protein. The effect of ambuic acid on the degradation of I $\mathrm{B}$ - $\alpha$ and the translocation of NF- $\kappa \mathrm{B}$ p 65 to the nucleus was investigated by Western blot analysis. As shown in Fig. 7A and B, LPS treatment induced the degradation of I $\kappa \mathrm{B}-\alpha$ protein and the translocation of NF- $\kappa \mathrm{B}$ p 65 to the nucleus. However, ambuic acid showed no obvious suppression on both the degradation of $\mathrm{IkB}-\alpha$ protein and the translocation of NF- $\kappa \mathrm{B}$ p65 to the nucleus. 


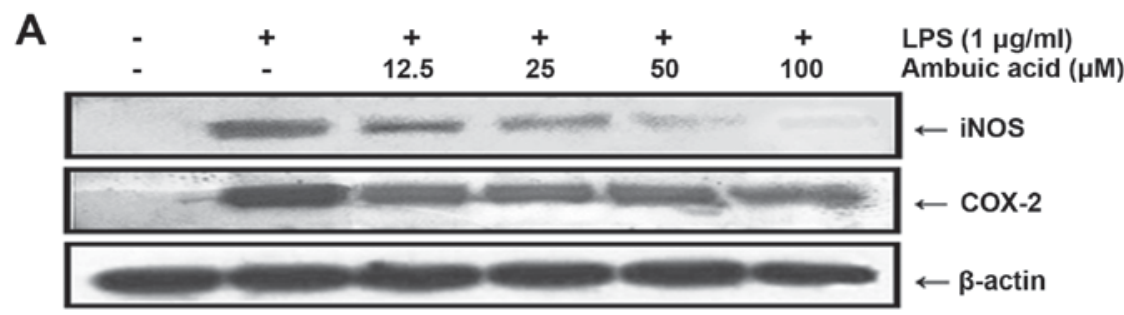

B

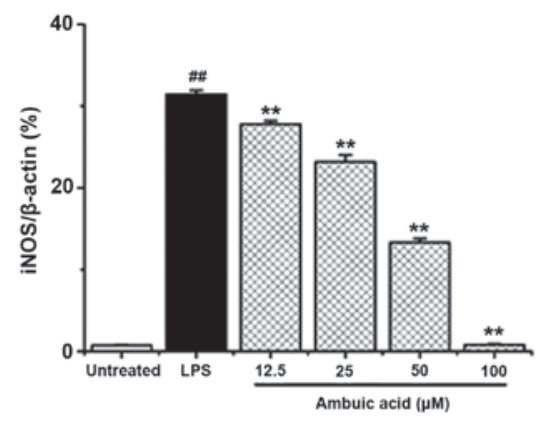

C

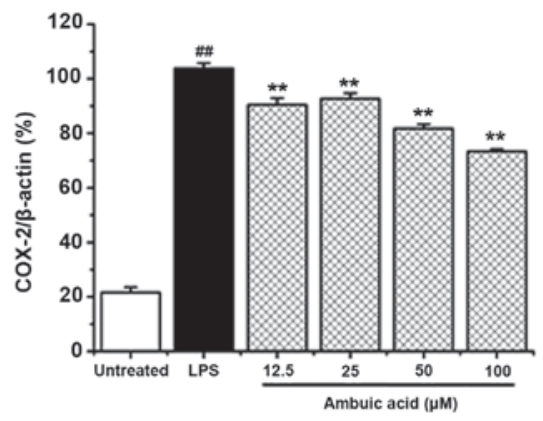

Figure 4. Effect of ambuic acid on the high expression of iNOS and COX-2 proteins induced by LPS. RAW264.7 cells were treated by LPS $1 \mu \mathrm{g} / \mathrm{ml}$ with or without ambuic acid $(12.5,25,50$ and $100 \mu \mathrm{M})$ for $24 \mathrm{~h}$, and the expression of iNOS protein and COX-2 protein was detected by (A) western blot analysis. To confirm the equal loading of proteins, the detection of $\beta$-actin was carried out. Densitometric analysis of (B) iNOS protein and (C) COX-2 protein is represented by mean \pm standard deviation of three separate experiments. Data were standardized on the basis of $\beta$-actin levels. ${ }^{\# \#} \mathrm{P}<0.01$ vs. untreated group; ${ }^{* *} \mathrm{P}<0.01$ vs. LPS treatment group. iNOS, inducible nitric oxide synthase; COX-2, cyclooxygenase-2; LPS, lipopolysaccharide.
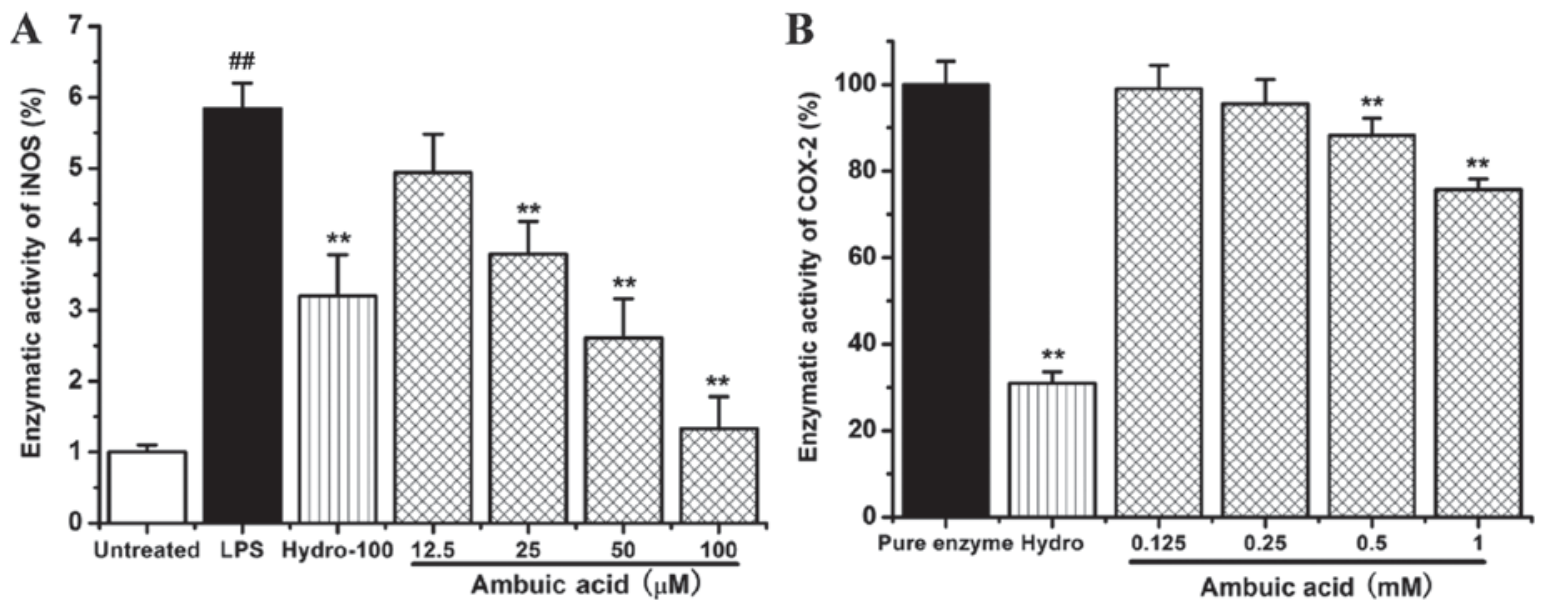

Figure 5. Effect of ambuic acid on the enzymatic activity of iNOS and COX-2. (A) RAW264.7 cells were treated by LPS ( $1 \mu \mathrm{g} / \mathrm{ml})$ with or without ambuic acid $(12.5,25,50$ and $100 \mu \mathrm{M})$ or hydrocortisone succinate $(100 \mu \mathrm{M})$ for $2 \mathrm{~h}$. The fluorescence was measured at an excitation of $485 \mathrm{~nm}$ and emission of $528 \mathrm{~nm}$ according to the described method. The levels of iNOS enzymatic activity were plotted as relative fluorescence units. ${ }^{\# \#} \mathrm{P}<0.01$ vs. untreated group; ${ }^{* * *} \mathrm{P}<0.01$ vs. LPS treatment group. (B) Inhibitory effect of ambuic acid $(0.125,0.25,0.5$ and $1 \mathrm{mM})$ and hydrocortisone succinate $(1 \mathrm{mM})$ on the COX-2 enzymatic activity was tested by the colorimetric method. The levels of COX-2 enzymatic activity were plotted as relative units compared to the pure enzyme. The experiment was repeated twice, and data are represented by mean \pm standard deviation ${ }^{* *} \mathrm{P}<0.01$ vs. pure enzyme group. iNOS, inducible nitric oxide synthase; COX-2, cyclooxygenase-2; LPS, lipopolysaccharide.

\section{Discussion}

Ambuic acid has been reported to show a certain inhibitory effect on a variety of plant pathogenic fungi Fusarium solani, Fusarium cubense, Helminthosporium sativum, Diplodia natelensis, Cephalosporium gramineum, Pythium ultimum (24), and it has a certain antimicrobial activity against the Gram-positive bacterium Staphyococcus aureus (26). Ambuic acid can also effect the biosynthesis of cyclic peptide quormones in Gram-positive bacteria Enterococcus faecalis (27). Our research group firstly found that ambuic acid significantly inhibited LPS-induced overproduction of NO, an important pro-inflammatory mediator that could promote the expression of some enzymes implicated in diverse human inflammatory diseases. These results imply the potential anti-inflammatory effect of ambuic acid and its related derivatives. The present study was designed to elucidate the anti-inflammatory effects of ambuic acid, as well as to elucidate its molecular mechanism. 
A
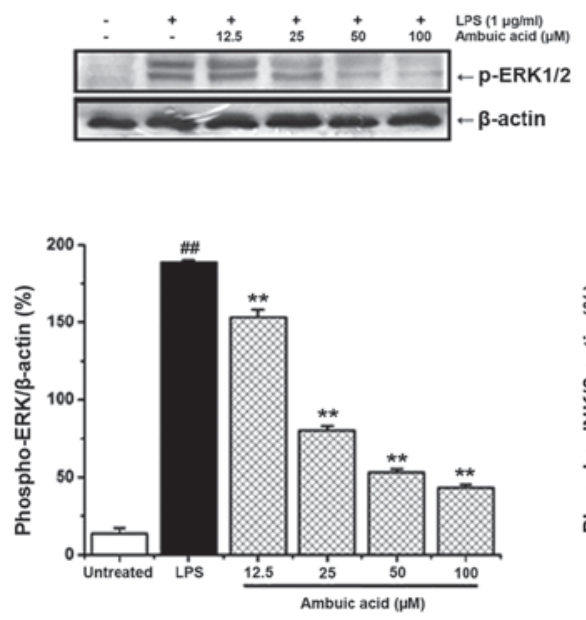

B

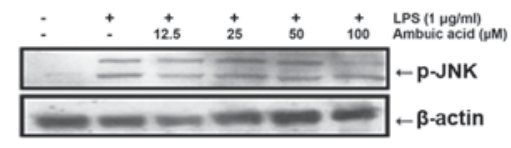

C

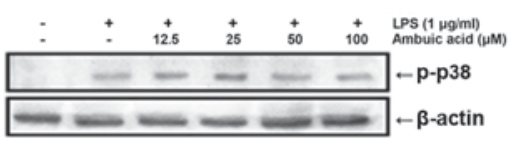

Figure 6. Effect of ambuic acid on the phosphorylation of ERK 1/2, JNK and p38 proteins induced by LPS. RAW264.7 cells were stimulated by LPS $(1 \mu \mathrm{g} / \mathrm{ml})$ with or without ambuic acid $(12.5,25,50$ and $100 \mu \mathrm{M})$ for $30 \mathrm{~min}$, and western blot analysis was used to investigate the expression of phospho-ERK $1 / 2$, phospho-JNK and phospho-p38 proteins. To confirm the equal loading of proteins, the detection of $\beta$-actin was carried out. Densitometric analysis of (A) phospho-ERK 1/2 protein, (B) phospho-JNK protein and (C) phospho-p38 protein is represented by mean \pm standard deviation of three separate experiments. Data were standardized on the basis of $\beta$-actin levels. ${ }^{\# \#} \mathrm{P}<0.01$ vs. untreated group; ${ }^{* *} \mathrm{P}<0.01$ vs. LPS treatment group. ERK, extracellular signal-regulated kinase; JNK, c-Jun N-terminal kinase; LPS, lipopolysaccharide.

A
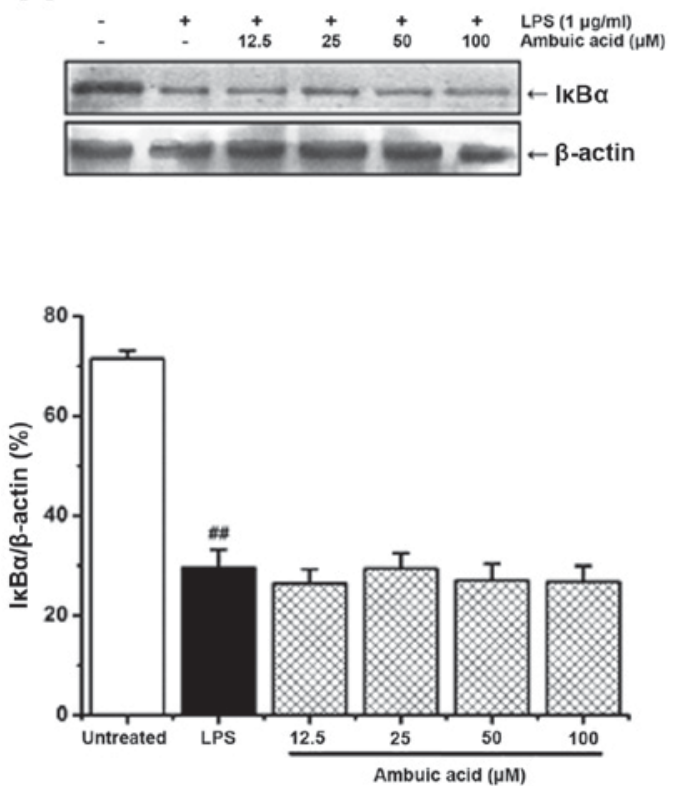

B
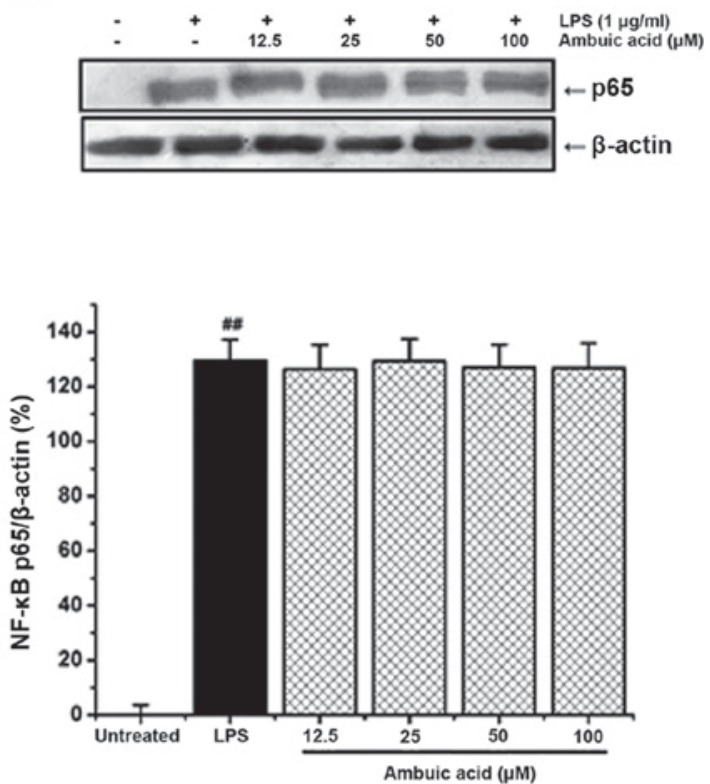

Figure 7. Effect of ambuic acid on the degradation of (A) IкB- $\alpha$ and (B) the nuclear translocation of NF- $\kappa$ B p65 induced by LPS. (A) RAW264.7 cells were stimulated by LPS $(1 \mu \mathrm{g} / \mathrm{ml})$ with or without ambuic acid $(12.5,25,50$ and $100 \mu \mathrm{M})$ for 10 min. Cytoplasmic protein was extracted and (A) western blot analysis was performed to investigate the level of IкB- $\alpha$ protein. RAW264.7 cells were stimulated by LPS (1 $\mu \mathrm{g} / \mathrm{ml})$ with or without ambuic acid (12.5, 25, 50 and $100 \mu \mathrm{M}$ ) for $45 \mathrm{~min}$. (B) Nuclear protein was extracted and western blot analysis was used to investigate the expression of NF- $\mathrm{B}$ p65 protein in the nucleus. Detection of $\beta$-actin was carried out to confirm the equal loading of proteins. Densitometric analysis of I $\kappa \mathrm{B}-\alpha$ protein and NF- $\kappa \mathrm{B}$ p65 protein are represented by mean \pm standard deviation from three separate experiments. Data were standardized on the basis of $\beta$-actin levels. ${ }^{\#} \mathrm{P}<0.01$ vs. untreated group. I $\mathrm{B}-\alpha$, inhibitory $\kappa \mathrm{B}-\alpha$; NF- $\kappa \mathrm{B}$, nuclear factor- $\kappa \mathrm{B}$; LPS, lipopolysaccharide.

As shown in the results, ambuic acid strongly inhibited various LPS-induced responses of macrophages including the $\mathrm{NO}$ overproduction, the $\mathrm{PGE}_{2}$ production, and the release of pro-inflammatory cytokine IL-6. This is the first direct evidence to show that the ambuic acid has an anti-inflammatory effect. To further investigate the possible anti-inflammatory molecular mechanism of ambuic acid, the effect on the expression of
iNOS and COX-2 proteins, the effect on the enzymatic activity of iNOS and COX-2 enzymes, the effect on the activation of MAPK pathway and NF- $\kappa \mathrm{B}$ pathway were further investigated.

The Toll like receptor is a superfamily of receptors that are mainly distributed in inflammatory cells to identify pathogen molecules, among them, TLR4 mainly identified the LPS that is the component of gram negative bacteria cell 
wall. Activation of myeloid activating factor 88 dependent and non dependent two signal pathway pathways in combination with LPS and TLR4. The former activates MAPK and NF- $\mathrm{B}$ signaling pathways, the latter activates the NF- $\kappa \mathrm{B}$ and interferon regulatory factor-3 (IRF3) signaling pathways. Through these signaling pathways, TLR4 induces inflammatory cells to release inflammatory factors that mediate inflammatory responses. RAW264.7 cells have been shown to express TLR4 in the literature, and LPS is able to recognize TLR4 receptors on macrophages and activate macrophages to produce inflammatory factors (39).

MAPK cascades have been shown to be important in the transduction of extracellular signals to cellular immune responses (40). In mammalian cells, three MAPK families have been clearly characterized: classical MAPK, also known as ERK, JNK/MAPK (JNK/SAPK) and p38 kinase. The MAPK pathways relay, amplify and integrate signals from a diverse range of stimuli, and elicit appropriate physiological responses, including inflammatory responses, cellular proliferation, differentiation and apoptosis in mammalian cells. LPS can activate the ERK, JNK and p38 MAPK signaling pathways, which can promote the production of pro-inflammatory cytokines and the expression of iNOS and COX-2 proteins $(41,42)$. Thus, the MAPK signaling pathways are vital approaches to regulate inflammatory responses, and are also considered suitable targets for anti-inflammatory therapy (43).

$\mathrm{NF}-\kappa \mathrm{B}$ plays an important role in many cellular responses to environmental changes so it is the most valuable transcription factor. NF- $\kappa \mathrm{B}$ complex containing the p50 and the p65 subunits exists in the cytoplasm in a latent form, which is stabilized by an inhibitory subunit called I $\kappa \mathrm{B}-\alpha(44,45)$. After stimulation of cells with LPS, I $\kappa \mathrm{B}-\alpha$ becomes phosphorylated followed by a rapidly protein degradation. As a result, $\mathrm{NF}-\kappa \mathrm{B}$ is activated and translocates into the nucleus promptly.

Our results demonstrated that ambuic acid strongly inhibited both the expression of iNOS protein and the enzymatic activity of iNOS enzyme in a dose-dependent manner, which strongly suggested that the decrease of NO production was due to the suppression of iNOS expression and enzymatic activity. Ambuic acid also inhibited the expression of COX-2 protein and the enzymatic activity of COX-2 enzyme, which indicated that the decrease of $\mathrm{PGE}_{2}$ production was due to the suppression of COX-2 expression and enzymatic activity. Further investigations showed that ambuic acid suppressed the phosphorylation of ERK and JNK proteins, but did not suppress the phosphorylation of $\mathrm{p} 38$ protein. Ambuic acid showed no obvious inhibition on the degradation of $\mathrm{I} \kappa \mathrm{B}-\alpha$ protein and the translocation of $\mathrm{NF}-\kappa \mathrm{B}$ to the nucleus. In conclusion, ambuic acid exerts anti-inflammatory effect through inhibiting LPS-induced production of much pro-inflammatory mediators such as NO, $\mathrm{PGE}_{2}$ and IL-6, and its molecular mechanism was proved to be via blocking the ERK/JNK MAPK signaling pathway but has no concern with the inactivation of $\mathrm{NF}-\kappa \mathrm{B}$ pathway.

The mechanism of inflammation is that LPS combines with TLR4 receptors on macrophages to stimulate the release of inflammatory factors such as NO, TNF- $\alpha$, IL-6 and $\mathrm{PGE}_{2}$, and can activate the high expression of upstream protein MAPK signaling pathway and downstream proteins iNOS and COX-2. In the experiment, the cells were cultured, and then add the ambuic acid after a period of incubation, the medium was changed, and the cells were washed to remove the medium of ambuic acid, then add LPS, it combines with the TLR4 cell receptor, which can prevent the reaction of LPS and ambuic acid, and appear the false positive results.

From the experimental results we can see that ambuic acid may have mediated changes in the production of inflammatory cytokines by RAW264.7 cells by influencing the ability of LPS to bind to TLR4. In the future studies will investigate the role of TLR4 in the ambuic acid-mediated reduction of pro-inflammatory cytokines in RAW264.7 cells and investigate the mechanisms underlying the ambuic acid-mediated reduction in pro-inflammatory cytokines using specific inhibitors of ERK and JNK.

\section{Acknowledgements}

Not applicable.

\section{Funding}

The present study was supported by the Ministry of Science and Technology of China (grant nos. 2014CB138304 and 2012ZX09301002-003), The National Nature Science Foundation (grant no. 21472233), The Youth Innovation Promotion Association of Chinese Academy of Sciences (grant no. 2014074) and The Shandong Provincial Natural Science Foundation (grant no. ZR2016HL54).

\section{Availability of data and materials}

All data generated or analyzed during this study are included in this published article.

\section{Authors' contributions}

HuL cultured the cells and detected the cytotoxicity of ambuic acid by MTT assay. YL and PL determined the concentration of nitric oxide and $\mathrm{PGE}_{2}$. LW and DL determined the concentration of TNF- $\alpha$ and IL-6. MW and QZo analyzed the enzymatic activity of iNOS and COX-2. Protein extraction was carried out by KM. The first authors QZh and RL detected the extracted protein by western blotting, and performed statistical analysis of the data; they were also major contributors in writing the manuscript. HoL purified and identified ambuic acid. HoL and FZ conducted the experimental design and manuscript writing. All authors read and approved the final manuscript.

\section{Ethics approval and consent to participate}

Not applicable.

\section{Consent for publication}

Not applicable.

\section{Competing interests}

The authors declare that they have no competing interests. 


\section{References}

1. Liu Y, Yang MH, Wang XB, Li TX and Kong LY: Caryophyllene sesquiterpenoids from the endophytic fungus, Pestalotiopsis $s p$. Fitoterapia 109: 119-124, 2016.

2. Deyrup ST, Swenson DC, Gloer JB and Wicklow DT: Caryophyllene sesquiterpenoids from a fungicolous isolate of Pestalotiopsis disseminata. J Nat Prod 69: 608-611, 2006.

3. Hwang IH, Swenson DC, Gloer JB and Wicklow DT: Disseminins and spiciferone analogues: Polyketide-derived metabolites from a fungicolous isolate of Pestalotiopsis disseminate. J Nat Prod 79: 523-530, 2016

4. Yang XL, Awakawa T, Wakimoto T and Abe I: Induced production of novel prenyldepside and coumarins in endophytic fung Pestalotiopsis acaciae. Tetrahedron Lett 54: 5814-5817, 2013.

5. Klaiklay S, Rukachaisirikul V, Tadpetch K, Sukpondma Y, Phongpaichit S, Buatong J and Sakayaroj J: Chlorinated chromone and diphenyl ether derivatives from the mangrove-derived fungus Pestalotiopsis sp. PSU-MA69. Tetrahedron 68: 2299-2305, 2012.

6. Li J, Li L, Si Y, Jiang X, Guo L and Che Y: Virgatolides A-C, benzannulated spiroketals from the plant endophytic funfus Pestalotiopsis virgatula. Org Lett 13: 2670-2673, 2011.

7. Xu J, Kjer J, Sendker J, Wray V, Guan H, Edrada R, Lin W, $\mathrm{Wu} \mathrm{J}$ and Proksch P: Chromones from the endophytic fungus Pestalotiopsis sp. isolated from the chinese mangrove plant Rhizophora mucronata. J Nat Prod 72: 662-665, 2009.

8. Harper JK, Arif AM, Ford EJ, Strobel GA, Porco JA Jr, Tomer DP, Oneill KL, Heider WM and Grant DM: Pestacin: A 1,3-dihydro isobenzofuran from Pestaliopsis microspora possessing antioxidant and antimycotic activities. Tetrahedron 59: 2471-2474, 2003

9. Akone SH, Amrani ME, Lin W, Lai D and Proksch P Cytosporins F-K, new epoxyquinols from the endophytic fungus Pestalotiopsis theae. Tetrahedron Lett 54: 6751-6754, 2013.

10. Xu J, Aly AH, Wray V and Proksch P: Polyketide derivatives of endophytic fungus Pestalotiopsis $s p$. isolated from the Chinese mangrove plant Rhizophora mucronata. Tetrahedron Lett 52 : 21-25, 2010.

11. Strobel G, Yang X, Sears J, Kramer R, Sidhu RS and Hess WM: Taxol from Pestalotiopsis microspora, an endophytic fungus of Taxus wallachiana. Microbiology 142: 435-440, 1996.

12. Kumaran RS, Kim HJ and Hur BK: Taxol-producing [corrected] fungal endophyte, Pestalotiopsis species isolated from Taxus cuspidata. J Biosci Bioeng 110: 541-546, 2010.

13. Tan RX and Zou WX: Endophytes: A rich source of functional metabolites. Nat Prod Rep 18: 448-459, 2001.

14. Ding G, Liu S, Guo L, Zhou Y and Che Y: Antifungal metabolites from the plant endophytic fungus Pestalotiopsis foedan. J Nat Prod 71: 615-618, 2008

15. Wei MY, Li D, Shao CL, Deng DS and Wang CY: $( \pm)$-Pestalachloride D, an antibacterial racemate of chlorinated benzophenone derivative from a soft coral-derived fungus Pestalotiopsis sp. Mar Drugs 11: 1050-1060, 2013.

16. Xu D, Zhang BY and Yang XL: Antifungal monoterpene derivatives from the plant endophytic fungus Pestalotiopsis foedan. Chem Biodivers 13: 1422-1425, 2016.

17. Jia YL, Wei MY, Chen HY, Guan FF, Wang CY and Shao CL: (+)- and (-)-pestaloxazine A, a pair of antiviral enantiomeric alkaloid dimers with a symmetric spiro[oxazinane-piperazinedione] skeleton from Pestalotiopsis sp. Org Lett 17: 4216-4219, 2015.

18. Chen L, Zhang QY, Jia M, Ming QL, Yue W, Rahman K, Qin LP and Han T: Endophytic fungi with antitumor activities: Their occurrence and anticancer compounds. Crit Rev Microbiol 42. 454-473, 2016

19. Kiho T, Itahashi S, Sakushima M, Matsunaga T, Usui S, Ukai S, Mori H, Sakamoto H and Ishiguro Y: Polysaccharides in fungi. XXXVIII. Anti-diabetic activity and structural feature of a galactomannan elaborated by Pestalotiopsis species. Biol Pharm Bull 20: 118-121, 1997.

20. Kumar DS, Lau CS, Wan JM, Yang D and Hyde KD: Immunomodulatory compounds from Pestalotiopsis leucothës, an endophytic fungus from Tripterygium wilfordii. Life Sci 78: $147-156,2005$

21. Verma VC, Gangwar M, Yashpal M and Nath G: Anticestodal activity of endophytic Pestalotiopsis sp. on protoscoleces of hydatid cyst Echinococcus granulosus. Biomed Res Int 2013: $308515,2013$.

22. Tejesvi MV, Kini KR, Prakash HS, Subbiah V and Shetty HS: Antioxidant, antihypertensive, and antibacterial properties of endophytic Pestalotiopsis species from medicinal plants. Can J Microbiol 54: 769-780, 2008.
23. Xia X, Kim S, Liu C and Shim SH: Secondary metabolites produced by an endophytic fungus Pestalotiopsis sydowiana and their 20S proteasome inhibitory activities. Molecules 21: pii: E944, 2016.

24. Li JY, Harper JK, Grant DM, Tombe BO, Bashyal B, Hess WM and Strobel GA: Ambuic acid, a highly functionalized cyclohexenone with antifungal activity from Pestalotiopsis spp. and Monochaetia sp. Phytochemistry 56: 463-468, 2001.

25. Harper JK, Barich DH, Hu JZ, Strobel GA and Grant DM: Stereochemical analysis by solid-state NMR: Structural predictions in ambuic acid. J Org Chem 68: 4609-4614, 2003.

26. Ding G, Li Y, Fu S, Liu S, Wei J and Che Y: Ambuic acid and torreyanin acid derivatives from the endolichenic fungus Pestalotiopsis sp. J Nat Prod 72: 182-186, 2009.

27. Nakayama J, Uemura Y, Nishiguchi K, Yoshimura N, Igarashi Y and Sonomoto K: Ambuic acid inhibits the biosynthesis of cyclic peptide quormones in gram-positive bacteria. Antimicrob Agents Chemother 53: 580-586, 2009.

28. Qi QY,Li EW, Han JJ, Pei YF, Ma K, Bao L, Huang Y, Zhao F and Liu HW: New ambuic acid derivatives from the solid culture of Pestalotiopsis neglecta and their nitric oxide inhibitory activity. Sci Rep 5: 9958, 2015.

29. Ali AM, Habeeb RA, El-Azizi NO, Khattab DA, Abo-Shady RA and Elkabarity RH: Higher nitric oxide levels are associated with disease activity in Egyptian rheumatoid arthritis patients. Rev Bras Reumatol 54: 446-451, 2014 (In Portuguese).

30. Coulter JA, McCarthy HO, Xiang J, Roedl W, Wagner E, Robson T and Hirst DG: Nitric oxide-a novel therapeutic for cancer. Nitric Oxide 19: 192-198, 2008.

31. Husain K, Hernandez W, Ansari RA and Ferder L: Inflammation, oxidative stress and rennin angiotensin system in atherosclerosis. World J Biol Chem 6: 209-217, 2015.

32. Beyazit Y, Efe C, Tanoglu A, Purnak T, Sayilir A, Taskıran I, Kekilli M, Turhan T, Ozaslan E and Wahlin S: Nitric oxide is a potential mediator of hepatic inflammation and fibrogenesis in autoimmune hepatitis. Scand J Gastroenterol 50: 204-210, 2015.

33. Muscará MN and Wallace JL: Nitric Oxide. V. therapeutic potential of nitric oxide donors and inhibitors. Am J Physiol 276: G1313-G1316, 1999.

34. Denizot F and Lang R: Rapid colorimetric assay for cell growth and survival. Modifications to the tetrazolium dye procedure giving improved sensitivity and reliability. J Immunol Methods 89: 271-277, 1986

35. Zhao F, Chen L, Zhang M, Bi C, Li L, Zhang Q, Shi C, Li M, Zhou $\mathrm{S}$ and Kong L: Inhibition of lipopolysaccharide-induced iNOS and COX-2 expression by indole alkaloid, 3-(hydroxymethyl)-6,7-dihydroindolo[2,3-a]quinolizin-(12H)-one, via NF- $\kappa$ B inactivation in RAW 264.7 macrophages. Planta Med 79: 782-787, 2013

36. Wohlmuth H, Deseo MA, Brushett DJ, Thompson DR, Macfarlane G, Stevenson LM and Leach DN: Diarylheptanoid from Pleuranthodium racemigerum with in vitro prostaglandin E(2) inhibitory and cytotoxic activity. J Nat Prod 73: 743-746, 2010.

37. Zhao F, Xu H, He EQ, Jiang YT and Liu K: Inhibitory effects of sesquiterpenes from Saussurea lappa on the overproduction of nitric oxide and TNF-alpha release in LPS-activated macrophages. J Asian Nat Prod Res 10: 1045-1053, 2008.

38. Zhao F, Wang L and Liu K: In vitro anti-inflammatory effects of arctigenin, a lignan from Arctium lappa L., through inhibition on iNOS pathway. J Ethnopharmacol 122: 457-462, 2009.

39. Murshid A, Gong J, Prince T, Borges TJ and Calderwood SK: Scavenger receptor SREC-I mediated entry of TLR4 into Lipid microdomains and triggered inflammatory cytokine release in RAW 264.7 Cells upon LPS activation. PLoS One 10: e0122529, 2015.

40. Liu Y, Shepherd EG and Nelin LD: MAPK phosphatases-regulating the immune response. Nat Rev Immunol 7: 202-212, 2007.

41. Arthur JS and Ley SC: Mitogen-activated protein kinases in innate immunity. Nat Rev Immunol 13: 679-692, 2013.

42. Rao KM: MAP kinase activation in macrophages. J Leukoc Biol 69: 3-10, 2001.

43. Kaminska B: MAPK signalling pathways as molecular targets for anti-inflammatory therapy-from molecular mechanisms to therapeutic benefits. Biochim Biophys Acta 1754: 253-262, 2005.

44. Baeuerle PA and Baltimore D: I kappa B: A specific inhibitor of the NF-kappa B transcription factor. Science 242: 540-546, 1988.

45. Beg AA and Baldwin AS Jr: The I kappa B proteins: Multifunctional regulators of Rel/NF-kappa B transcription factors. Genes Dev 7: 2064-2070, 1993. 